\title{
Cooperation among nations
}

\author{
Elizabeth Kay \\ EBD Editor
}

\section{$\mathrm{T}$}

he recent Olympic games, which I loved - despite the missing audiences and the strange, somewhat eerie atmosphere at some of the events - reminded me how much of a role internationalism now plays in everyone's lives. Little that we do is not touched by it. And indeed, some of the most important and major scientific breakthroughs would never, ever have been achieved by purely national efforts. Since World War II, scientists have cooperated across national boundaries, and every scientist must shudder at the populist and nationalistic view which suggests that the science of one or another country has superiority over any other. But scientists must, if they wish to resist the tide of populism and anti-globalism, ensure that their important findings and discoveries do not seem valueless and esoteric to the 'man in the street'. They need to translate their work into innovations that transform and improve the world and people's lives, but most importantly, scientists must seek and also insist upon truth. Scientists do not deal in opinion, or rhetoric, or by appealing to the public mood. They establish truth...an increasingly rare commodity, it sometimes seems, in this age of social media and sometimes dubious marketing methodologies. We scientists are able to utilise established and powerful techniques to establish truth, and we must take care, as this journal does, to sift evidence, separate fact from hyperbole and objectively examine the facts. I believe it is also part of our work to stand up and reject falsehood, whenever we see it.

Additionally, we must here consider the recent COVID-19 crisis. Crises often help radical change to occur because they unsettle the status quo. In addition, international crises such as the pandemic, however ghastly, do create space for new ways of thinking and new habits, as we have seen. When things are very difficult, it is then that people realise the need for more, rather than less, international cooperation. Crises, particularly at a global level, help us to overcome hurdles that previously seemed insurmountable. The shift in EU debates about a joint rescue and stimulus programme is one example, the mobilisation of many governments in favour of the World Health Organisation is another. Turning this momentum into a sustained improvement in global science will be difficult. But imaginative efforts with ambitious goals, bringing together scientists such as

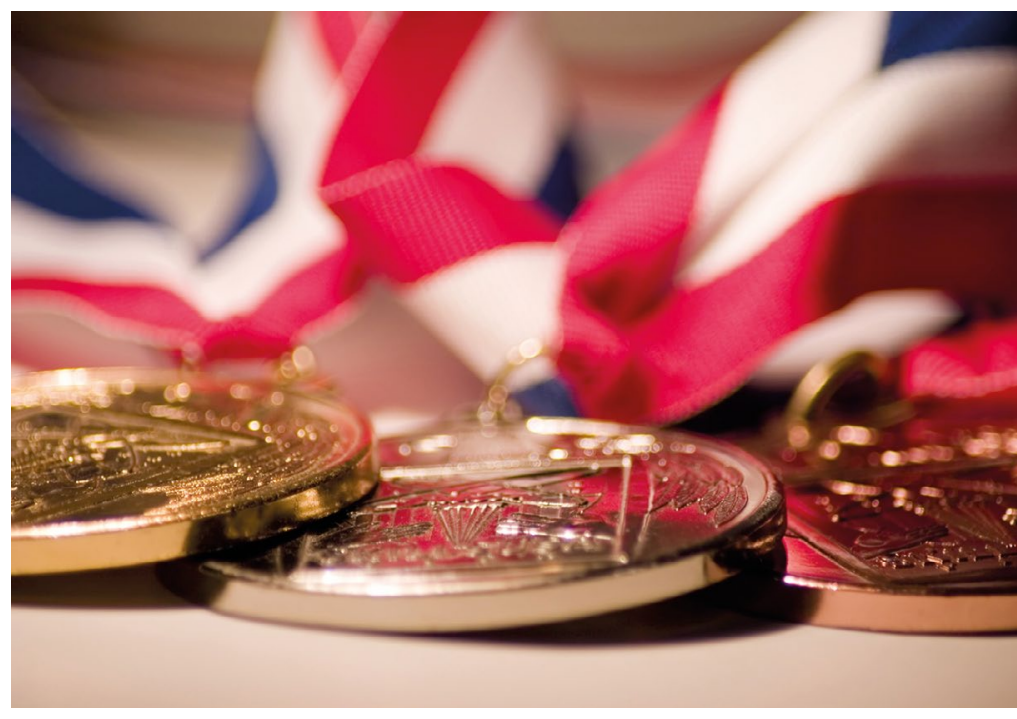
yourselves, may still yield important results. In the current storm, international cooperation needs active and determined support, or it may face gradual or even sudden decline.

Global science is different from the technological and commercial globalism which terrifies so many, and is largely responsible for the retreat to populism and nationalism seen in many countries around the world. If we stick to our dearly held principle of facts being based on empirical evidence, and continue to defend our international efforts to establish universal truths in our profession, we can perhaps help the world to see the value of fact-based, rather than opinion-based, organisations and institutions.

We, if we are internationalists, must also take care to ensure that, at the end of the day, our research efforts and our projects, and our reviews, offer benefit to society - and in the case of Evidence-Based Dentistry, to the dayto-day lives that dentists inhabit with their patients. While funding for dental research is sometimes hard to come by, the dental scientists who undertake research simply to generate funding and acquire academic honours and prizes, rather than publishing work which has a bearing on human welfare, do our profession a great disservice.

We are proud at Evidence-Based Dentistry that we are truly international.
We have an international Editorial Board and our marvellous commentators who give so much to this journal, and to the establishment of useful facts to enhance dentistry worldwide, are from almost all corners of the globe. And for any of you who might be reading this and thinking that you could write for this journal, but that it is for a different population than yours, you are wrong. If you feel that you would like to contribute to dentistry's quest to be thoroughly based in evidence and thoroughly international, please contact me about being a commentator. You would need to be familiar with the techniques of systematic reviewing and of the correct ways to analyse data from randomised controlled trials and cohort studies, but if you are, please - wherever you are based - help us to make this journal even more international than it is now.

Please also remember, wherever you are, that we are now accepting systematic reviews...but only if their subject matter is of direct relevance to a dentist in general dental practice. By doing so, we hope to bring practitioners clarity about the best techniques, interventions, examinations and materials available to them.

Evidence-Based Dentistry (2021) 22, 88.

https://doi.org/ 10.1038/s41432-021-0189-8 